a tendência à emergência de uma cada vez mais importante faixa de terceira idade. O numero crescente de mulheres que trabalham fora do lar deverá também redefinir a divisão sexual do trabalho, a divisão sexual das emoçôes e a divisão sexual do trabalho emocional (Venosa, Roberto. "Divisão Sexual do Trabalho, Divisão Sexual das Emoçôes, Divisão Sexual do Trabalho Emocional", artigo a ser publicado em breve). Uma derradeira nota para aqueles que, embora tenham achado "interessante", acreditem que já não tenham tempo para investir em outros tipos de leitura: Peter Laslett iniciou sua vida acadêmica em Cambridge como Professor de História e Teoria Política.
Depois de vinte anos ensinando Politica e História, fundou o Centro para a História das Populações e das Estruturas Sociais e, embora aposentado formalmente, năo deixa de comparecer aos coffee-breaks das sextas-feiras. Sempre às 11 horas, algumas vezes usando sua cambridgeana gravata borboleta. Quando The World We Have Lost foi publicado pela primeira vez, Peter já estava beirando os 50 anos.

The World We Have Lost é um livro escrito por um erudito Professor do Trinity College, em Cambridge, e de leitura muxto agradável, talvez mesmo agradável só para confrontar com a tradição hístóricodemográfica na França, na qual se escreve difícil para não ser entendido. $\square$

\title{
IN THE AGE OF THE SMART MACHINE - THE FUTURE OF WORK AND POWER
}

\author{
SHOSHANA ZUBOFF \\ New York, Editora Basic Books, Inc., Publishers, 1988.
}

Por Edith Seligmann Silva, Professora Adjunta do Departamento de Fundamentos Sociais e duridicos da Administração da EAESP/FGV e Professora Adjunta do Departamento de Medicina Preventiva da Faculdade de Medicina da Universidade de São Paulo.

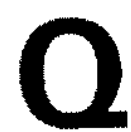
uais, exatamente, as transformaçôes que a informatização acarreta para a administração? De que modo se alteram as relações de poder e as relaçóes interpessoais dentro da empresa quando a tecnologia coloca ao alcance de todos informaçóes que, antes da introdução do computador, só eram acessadas pelos administradores? Por que o aproveitamento pleno dos potenciais oferecidos pela tecnologia de informação exigem uma nova sociabilidade $e$ no que consistem as novas aptidões psicossociais essenciais à intercompreensão e à interatividade? $\mathrm{E}$, finalmente, quais os cenários futuros que se descortinam diante do administrador?

A autora esclarece, no limiar de seu livro, a posição que decidiu adotar como ponto de partida para seu estudo: "As opçoses para o futuro nēo podem ser deduzidas a partir de dados econômicos ou de mediçôes abstratas do funcionamento organizacional. Elas estão inseridas nos detalhes vivos do cotidinno da vida no trabalho em que as pessoas comuns confrontam os dilemas levantados pelas caracteristicas transformadoras da nova tecnologia de informatizaçăo. Por esta razano a pesquisa aqui apresentada ilumina a fextura da experiencia humana - o que as pessoas dizem, sentem e fazem - no lidar com as mudanças tecnológicas que impregnam seu ambiente imediato."

Propondo-se estudar os desafios e as alternativas que a informatização coloca para os administradores, a autora pesquisou longitudinalmente oito grandes organizaçôes. A investigação incluiu indústrias e escritónios. Dentre as empresas estudadas, figurou um banco de grande porte. Foi possivel realizar estudo comparativo entre três indústrias do ramo de papel e celulose que se diferenciavam entre si, tanto pelas lógicas administrativas 
adotadas quanto pelo fato de que a informatização havia sido implantada nas mesmas em circunstâncias diferentes substituindo tecnologia tradicional em dois casos, enquanto no terceiro a indústria já fôra planejada para ser computadorizada.

A construção da obra apóia-se num amplo referencial bibliográfico, no qual teorias e conhecimentos elaborados em diferentes áreas cientificas e correntes de pensamento são integrados por Shoshana Zuboff. Assim, a autora parte de uma perspectiva filosófica calcada na História, para recolher contribuiçóes de autores do campo da Sociologia, da Ciência Política, da Antropologia, da Psicologia Social e muito especialmente da Psicologia Cognitiva. Uma abordagem aprofundada da relevància dos padrões de comunicação interpessoal para a criação de condições de interatuação criativa é realizada a partir da obra de Basil Bernstein. Diferentes estudos de Sociologia do Trabalho e da área de Administração servem de parâmetro ao estudo de campo da autora. A revisão crítica de pesquisas anteriores realizadas em indústrias de processo contínuo, e que também analisaram os impactos humanos e administrativos da implantação de novas tecnologia e forma de organização do trabalho, tambêm faz parte do livro. Tudo isto sem que a autora passe ao largo da Economia Política ao examinar a origem das determinaçōes que conduzem às dinamicas organizacionais e psicossociais. $O$ fio condutor que integra as concepçōes e abordagens analisadas, construindo seu sentido, emerge da História e de correntes de pensamento que para ela confluem. Norbert Elias, Fernand Braudel e Michel Foucault foram chamados por Zuboff para essa construção, na qual comparecem iluminando o passado e o presente do trabalho humano, ao mesmo tempo que ajudam a delinear o seu porvir.

$\mathrm{Na}$ introdução, a autora descreve de modo sintético e claro o processo de informatização e o de automatização, esclarecendo distinçôes nem sempre consideradas. Além de colocar à disposiçẫo do leitor não especializado $\mathrm{cm}$ informática e automação explicaçoes propiciadoras de fácil entendimento, aponta para alguns aspectos da inteligềncia embutida nos computadores.

A primeira parte do livro recebe o título "Conhecimento e o trabalho mediado pelo computador". Em seu primeiro capítulo trata da trajetória histórica do conhecimento no interior do mundo do trabalho. O segundo capítulo concentra-se na emergència da abstração no trabalho industrial e da radical mudança que esta emergência significou nas empresas estudadas, tanto para operadores de processo quanto para gerentes. Nos capitulos seguintes, são especialmente analisadas as transformaçoes que a informatização trouxe para os escri. tórios, simultaneamente para várias categorias de atores do trabalho e muito especialmente para os executivos. As novas habilidades e a construção do sentido, implícitas na "dominação do texto eletrônico", ocupam o último capítulo desta primeira parte da obra.

A segunda parte da obra, denominada "Autoridade: a dimensão espiritual do poder", trata justamente dos dilemas e desafios mais especificamente relacionados à questão do poder, culminando no capítulo que examina os limites assumidos pela hierarquia nas organizações informatizadas.

As formas pelas quais a técnica materializa o poder nos sistemas computadorizados se constituem no objeto da terceira parte. A discussão das opções referidas ao fantástico poder de controle embutido nos novos equipamentos centraliza esta parte, com base nas evoluçōes que tiveram lugar considerando as diferentes alternativas administrativas assumidas nas empresas analisadas pela autora. No final desta parte, Zuboff também examina as tendências internacionais recentes da organização do trabalho em empresas informatizadas e os novos desafios colocados aos administradores numa era "pós-hierárquica".

Os principais procedimentos adotados na pesquisa de campo foram entrevistas e observações nos locais de trabalho. Zuboff entrevistou membros da alta direção das organizaçōes estudadas, gerentes de diferentes áreas e níveis, empregados dos escritorios e operadores das plantas industriais. A par disto, a autora realizou observação participante, convivendo períodos prolongados nos ambientes pesquisados. 
Recebe atenção especial por parte da autora a importância que assume presentemente para o administrador o conhecimento dos processos mentais humanos individuais e coletivos - e o modo como os mesmos sâo atingidos e modificados pelas transformaçoes organizacionais $\mathrm{e}$ tecnológicas do trabalho.

Cabe à administraçăo um papel muito especial na promoção da auto-estima e do interesse dos empregados, quando sistemas altamente sofisticados sầ vistos pelos operadores como dotados de "um poder de inteligência tão próximo à perfeição que diminui qualquer valor do envolvimento humano". Trata-se, nestes casos, do desafio de evitar o surgimento dos sentimentos de dependencia que, além de esfriar a motivação, congelam a criatividade.

Ao estudar os significados sócio-psicológicos e culturais associados às mudanças dos tipos de aptidões requeridas pelas novas atividades, Shoshana Zuboff examina em profundidade alguns aspectos essenciais: a dinâmica psicossocial presente na construção do sentido; e o modo pelo qual novos padróes de rela§̧ões interpessoais modificam a cultura organizacional pré-existente. Nesta, geralmente a competiçāo individual havia sido anteriormente objetivo de estímulo, ao passo que agora o objetivo é obter altos niveis de cooperação no interior dos grupos de trabalho. Os processos em que elementos dessa nova cultura se desenvolvem, bem como as barreiras que se opöem à mudança a partir de múltiplos hábitos, tradições e esterốtipos subsistentes, são igualmente alvo de análise.

Os exemplos extraídos das observações realizadas conferem grande poder elucídativo à argumentaçăo teóríca da autora. Citemos um destes exemplos ilustrativos: aquele em que Zuboff trata dos desafios advindos pela introduçẫo do texto eletrônico. Uma vez realizada essa introdução, as informaçōes integradas no texto não podiam mais ser compreendidas, em todo o seu alcance, por um único indivíduo, pois haviam passado a reunir dados correspondentes a conhecimentos detidos por especialistas distintos. Portanto, a decodíficação que passou a exigir uma interação cooperativa corresponde tanto a uma demanda de novas habilida- des psicológicas, quanto de novas aptidões sociais. Reconhecer e apoiar o desenvolvimento destas habilidades psicossociais significa incorporar novos valores e, por conseguinte, uma transformação de ordem cultural - o mais complexo e delicado dos desafios, considerando-se todo o acervo de estudos que a Antropologia nos oferece sobre a gradualidade em que geralmente se processa a mudança cultural.

Analisando as experiências das empresas estudadas, Zuboff identifica um novo desafio percebido por vários administradores: a criaçăo de uma nova lógica administrativa. Essa lógica teria que tomar por base a constatação de que o potencial da tecnologia informatizadora só pode ser integralmente aproveitado se igualmente os potenciais humanos daqueles que atuam no processo de trabalho são plenamente respeitados e reconhecidos. $O$ próprio compartilhamento do conhecimento, nesta nova lógica, deverá contribuir de modo importante para que possa ser estabelecida a confiança recíproca, essencial à intercomunicação significativa. Pois as pesquisas realizadas pela autora demonstram que o conhecimento compartilhado não pode restringir-se ao conhecimento dos equipamentos e de seu funcionamento. A filosofia da empresa, seus critérios e objetivos referentes à utilizaçäo da tecnologia de informação, bem como sua política e seus planos para o futuro também devem fazer parte deste conhecimento. Pois todos os empregados sabem que seu próprio futuro - desde a permanência no emprego até as perspectivas de carreira dependem igualmente destes planos. Somente com este conhecimento abrangente pode ser estabelecida a confiança - elemento que também merece acurado estudo da autora quanto ao significado que assume para o desenvolvimento da responsabilidade e do comprometimento.

A autora não chega a deter-se na dinâmica que vem sendo estudada por autores do campo da Psicopatologia do Trabalho no que diz respeito ao desenvolvimento de depressões, uso excessivo de bebidas alcóolicas e outros distúrbios psiquiátricos e psicossomáticos que vêm sendo examinados em sua vinculação ao trabalho mediado por computador. Nâo obstante, a dinâmica que Zuboff identifi- 
ca, ao estudar a questão da dependência e da perda de motivação, apresenta estreita correlação com estes estudos.

As observaçóes da autora, realizadas em contexto distinto do brasileiro, poderäo certamente propiciar amplas reflexões sobre como dilemas enfocados no livro deverão ser enfrentados dentro das especificidades sócioculturais da nossa realidade e de suas diversidades.

$O$ alcance principal deste livro, entretanto, parece ser a abertura de uma perspectiva administrativa para aqueles que se disponham a desencadear as inovações organizacionais requeridas para enfrentar os desafios de uma informatização que, de modo profundamente integrado, promova ganhos de qualificação, de qualidade de vida no trabalho e de competividade.

\section{NOTAS BIBLIOGRÁFICAS}

1. BERNSTEIN, Basil Class, Codes and Contro: theoreticat studies towards a Sociology of Language. Nova lorque, Shocken Books, 1975.

2. BRAUDEL, Ferrand. The Wheets of Commerce: civilization and captatism 15th-18th Century. Nova lorque. Harper \& Fow. 1982.

3. ELIAS, Norbert. The Civiling Process: the history of manners. Nova lorqua, Urizen Books, volume 1, 1978 The Civitzing Process: power and civility. Nova lorque, Pantheon, volume 2, 1982. (0s dois iá foram traduzidos no Brasil pela Jorge Zahar Editora, Aio de Janeiro, 1990.

4. FOUCAULT, Michel. In Colin Gordon (org.) Powerknowledge: selected intervitews and other wh tings 1972-1972. EUA, Pantheon Ed., 1980.

5. Discipline and Punish: the birth of the pri son. Nova lorque, Vintage Books, 1979. (Em adičco brasileira: Viglar e Punir-História da Violência nas Prisões, Editora Vozes, 1977.)山

\section{THE SPIRIT OF JAPANESE CAPITALISM AND SELECTED ESSAYS}

Por Gilmar Masiero, doutorando em Administração na EAESP/FGV.

A coleção Bíblioteca do Japã̃o é um esforço conjunto dos governos japonês e americano no sentido de coletar as melhores obras de ficção e não ficço escritas em japonès e traduzi-las para o inglês, tornando-as acessiveis aos leitores que dominam esse idioma. $\mathrm{O}$ objetivo explícito da coleção, que conta em seu conselho editorial com nomes ligados ao estudo da sociedade japonesa mundialmente reconhecidos, como Frank B. Gibney, Daniel J. Boorstin, Chalmers Johnson, é o de tornar o leitor médio americano consciente das, riquezas econômica e cultural da hoje segunda potência econồmica mundial.

Muito se produziu no pós-guerra para dar conta do fenômeno de desenvolvimento econômico acelerado da sociedade japonesa. Estudiosos ocidentais restritos pelas fronteiras delimitadoras de suas profissöes, para não falarmos de dificuldades idiomáticas ou do valor econômico de seu saber, são limitados também por sua própria formação temporal linear característica das sociedades judaicocristâs.

A circularidade temporal, característica da sociedade japonesa, está presente (porém não discutida diretamente) na obra de Yamamoto que procura dar respostas às origens e ao desenvolvimento do capitalismo japonês. Capitalismo este que, segundo ele $e_{r}$ centra-se mais no dinamismo das pequenas e médias empresas que nas tão estudadas e discutidas grandes corporaçoes. Centra-se muito mais no desenvolvimento de um tipo de socie- 